\title{
A STUDY ON LEARNING DIFFICULTIES RELATED TO DYSCALCULIA AND MATHEMATICAL ANXIETY
}

\author{
*Anna Vintere \\ Latvia University of Life Sciences and Technologies, Latvia \\ *Corresponding author's email: Anna.Vintere@1lu.lv
}

\begin{abstract}
This article discusses two math learning disorders: dyscalculia and mathematical anxiety. Dyscalculia is a cognitive disorder, math anxiety - emotional. Dyscalculia is a mathematics learning difficulty which is a brain-based condition connected to information organization and proceeding. In turn, mathematical anxiety is one of the emotional factors that causes learning difficulties in mathematics. Therefore, to promote progress in mathematics, the aim of this study is to identify learning difficulties in mathematics from the perspective of teachers and parents, to identify existing experiences in overcoming these learning difficulties in mathematics, and to determine the support needed by teachers. To achieve this goal, both parents and teachers have been surveyed as part of this study. About one-fifth of students have signs of dyscalculia, but $25 \%$ - mathematical anxiety. In Latvia, the most problematic type of dyscalculia is the ability to perform mathematical activities and perform both operational and practical calculations, but mathematical anxiety is equally common at all stages of education. According to a survey of teachers, only $7 \%$ of students have no mathematics learning difficulties. Parents associate children's learning difficulties with the organization of the learning process (intensive curricula, when the teacher does not have the opportunity to implement a differentiated / individual approach), as well as teachers' attitudes. Research shows that teachers are unable or unaware of how to determine whether a student has dyscalculia or math anxiety and do not have appropriate skills, know-how or training to help a student who experiences learning disabilities and difficulties with mathematics.
\end{abstract}

Key words: dyscalculia, mathematical anxiety, mathematics learning difficulties, survey.

\section{Introduction}

Mathematics is one of the logical and practical academic disciplines to be acquired as a key competence in the context of lifelong learning (EU, 2006, 2018). The importance of mathematics in daily and professional life as well as the fact that level of the mathematical competence influences the quality standards of individual and social life has been proved by several studies. However, learners' knowledge of mathematics is deteriorating year by year and mathematics is one of the reasons for dropping out at all levels of education. For example, in Latvia, based on the data provided by the State Education Content Centre, students demonstrate low result in the centralized mathematics exam every year. In 2016, it was $36.2 \%$, in $2017-34.9 \%$, in $2018-8.8 \%$, but in $2019-32.7 \%$, which is $1.9 \%$ points less than in the previous year. The results of 2020 are not taken because the exam was shortened due to the Pandemic. The results often are associated with the laziness, lack of motivation or other circumstances of the learner. However, if a student has not learned something, has not done homework, is not studying, it does not always indicate laziness or unwillingness to do it. In many cases, this indicates that the student is having difficulty learning math and may not be able to learn mathematics.

Mathematics learning difficulties are determined by a number of cognitive and emotional factors. If a student has calculation difficulties, impaired understanding of numerical concepts and mathematical activities, difficulties in understanding and working with numerical information without words, visually and spatially, often makes calculation errors and has difficulty performing mathematical activities, then this may be a mathematics learning difficulty such as dyscalculia (Rotzer et al., 2009). It should be noted that this is not a disease, but a feature of the pupil's brain that determines the perception and processing of information. However, several studies show that the mathematical performance of a student with dyscalculia is much lower than expected for age, intelligence and education (Büttner \& Hasselhorn, 2011).

In turn, mathematical anxiety is one of the emotional factors that causes learning difficulties in mathematics (Dowker, Sarkar, \& Looi, 2016). The term 'mathematical anxiety' is described as fear of math or as a negative emotional reaction to mathematics. Several researchers have found that mathematical anxiety can be caused by a number of factors: lack of appropriate mathematical knowledge, learning strategies, application of mathematics in real life, limited exam time, lack of specific materials as well as personality type, lack of confidence, and also stereotypes related to teacher and parent approaches to mathematics (Ashcraft \& Ridley, 2005; Finlayson, 2014; Hoffman, 2010; Maloney \& Beilock, 2012).

Despite the low achievement of students in mathematics, as evidenced by both the results of the centralized exams and the findings of International Comparative Studies, there is little research on mathematics learning difficulties such as dyscalculia and mathematical anxiety in Latvia. It should be noted that teachers also have insufficient experience in this field and are not familiar with strategies that 
can help students develop the necessary mathematics skills.

Studies show that students' mathematical achievement increases when anxiety is controlled (Kamann \& Wong, 1993; Maloney \& Beilock, 2012), but dyscalculia lasts a lifetime. Of course, performance can improve if intensive developmental action is taken. The student needs to gain an understanding of how to use mathematics in everyday life; parents and teachers need to work together to identify the strategies needed (Turkington \& Harris, 2006). Scientists suggest that the link between dyscalculia and/ or mathematical anxiety and performance can be driven. Therefore, to promote progress in mathematics, the aim of this study is to identify learning difficulties in mathematics from the point of view of teachers and parents, to identify existing experiences of overcoming these learning difficulties in mathematics, and to determine the support needed by teachers. To implement this aim, a survey of both parents and teachers has been conducted within the framework of this study.

\section{Materials and Methods}

In Latvia, special education specialists have gathered work experience with learners with learning and visual disorders. This material also identifies students' difficulties in learning mathematics (Tūbele et al., 2013):

1) Insufficient knowledge about the composition of the number, difficulties to learn laws on the formation of numbers;

2) Insufficient understanding of positive and negative values;

3) Understanding of quantitative (numerical) relations of numbers is not developed;

4) Automatically reproduces a sequence of numbers;

5) Difficulty in understanding the sequence of information or events;

6) Sometimes difficulties in understanding the concepts that apply to such categories such as days, weeks, months, seasons, quarter, etc.;

7) Difficulties in determining the relationship of a number to adjacent numbers;

8) Difficulties in determining the position of a number in a series of natural numbers;

9) Difficulty to perform mathematical operations step by step in a certain order;

10) Insufficiently mastered collection of mathematical concepts;

11) Incorrect naming of numbers;

12) Inaccurate idea of digital graphic structure;

13) Elementary method of performing arithmetic operations (child counts on the fingers);

14) Does not know addition and subtraction, multiplication and division tables;
15) Difficulty in handling money;

16) Sometimes difficulty navigating a sheet of paper, writing numbers in columns, navigate long calculations;

17) Thinking operations are mostly specific;

18) Other difficulties.

To develop the methodology of this study, a study of the scientific literature on dyscalculia and mathematical anxiety was performed, considering the above-mentioned mathematical learning difficulties. In the case of dyscalculia, the symptoms can be very different: very poor mathematical ability, problems in using money, fear of money and transactions with it, unable to fully understand the meaning of numbers and evaluate numerical values, problems with such mathematical activities as addition, subtraction, multiplication and with concepts such as sequence, which can be combined with a poor understanding of directions, inability to read a map, understanding time, time schedule, observance of time, sequence of past and future events (Turkington \& Harris, 2006). Dyscalculia is linked to problems representing magnitude of numbers, poor working memory (the ability to hold information in mind whilst performing another task), difficulties with inhibition, poor spatial skills or problems organising sounds (Devine et al., 2017).

As can be seen, several scientists have studied and identified various signs of dyscalculia. Dyscalculia is a specific learning disability in mathematics: difficulty to understanding number-related concepts or using symbols or functions needed for achievement in mathematics, difficulty with the mechanics of doing math, such as being able to recall mathematical facts and/ or difficulty to apply what they know to solve mathematical problems. The survey conducted within the framework of this study is based on types of dyscalculia, which were identified by researcher L. Kosc (Kosc, 1974), namely:

1) Verbal manifestation of difficulties in verbally denoting mathematical concepts;

2) Practically Gnostic, in which the systems of counting (calculating) specific and apparent objects or their symbols are disturbed;

3) Dyslexic, which is based on mathematical sign reading disorders;

4) Graphic, which manifests itself as a malfunction of mathematical notation and correct representation of geometric figures;

5) Operational, associated with inability to perform mathematical operations.

Mathematical anxiety is described in this study as the anxiety, tension, or discomfort experienced by many students in performing mathematics or daily activities in a mathematical context (Richardson \& Suinn, 1972). Studies show that anxiety impairs the 
ability to keep in mind and manipulate information, which is mostly an emotional problem (Ashcraft \& Krause, 2007). In this study, questions for measuring math anxiety are based on four factors: test anxiety, physical anxiety, out-of-work behaviour, and social anxiety (Carey et al., 2017).

Dyscalculia and mathematical anxiety are different, but the signs and struggles can overlap. Some students may have both math anxiety and dyscalculia.

Dyscalculia is a mathematics learning difficulty which is a brain-based condition connected to information organization and proceeding. In turn, mathematical anxiety is one of the emotional factors that causes learning difficulties in mathematics.

Based on the above scientific considerations, a questionnaire for teachers was developed (Table 1).

The questionnaire for parents was based on the teachers' questionnaire, asking similar questions that determined the type of dyscalculia or mathematical anxiety. The questionnaire (in English) for parents is available at: https://ej.uz/Math parents_En, for teachers: https://ej.uz/Math_teachers_En. In total 33 parents and 67 teachers took part in this study. Information on the respondent included only the age of the children (parents) or the level of education with which the teachers work.

It should be noted that the questionnaires are common for all the age ranges. They include questions that provide answers to questions about the difficulties of learning mathematics for students of any age. Some questionnaire responses are measured on a four-level Likert scale: always, often, sometimes, and never. Only one question is open-ended. As the idea of the problem is based on the need for cooperation between family and teachers, it is very important to use this opportunity, which is the basis of this study. Therefore, it should be noted that this was a case study, and a selfassessment method was used in the study.

\section{Questions for teachers to identify math learning disorders}

\begin{tabular}{|c|c|}
\hline Sections & Appropriate questions \\
\hline $\begin{array}{l}\text { Learning } \\
\text { difficulties }\end{array}$ & $\begin{array}{l}\text { Would you be able to identify a case of dyscalculia among your student body? } \\
\text { Do you think that the amount of time devoted to the teaching of Maths is enough? }\end{array}$ \\
\hline $\begin{array}{l}\text { Types of } \\
\text { dyscalculia }\end{array}$ & $\begin{array}{l}\text { 1. Verbal: Do your pupils know how to articulate their doubts using mathematical language, } \\
\text { according to their ages? } \\
\text { 2. Verbal and dyslexic: Do your pupils understand the problem statements (spoken or written) and } \\
\text { the way to solve them? } \\
\text { 3. Graphic: Do your pupils have difficulty in writing numbers clearly or keeping their work neat } \\
\text { when solving math problems? } \\
\text { 4. Operational: Do your pupils struggle (make mistakes) while solving basic mental arithmetic? } \\
\text { 5. What do you think is the main mathematics learning difficulty among your student body? } \\
\text { - Verbal: Understand and verbalize mathematical concepts; } \\
\text { - Operational: Struggle when comparing sizes or quantities; } \\
\text { - Operational and practical: Solve arithmetical mental calculations; } \\
\text { - Dyslexic: Struggle to identify mathematical signs like + and - and to use them the right way } \\
\text { or has trouble understanding number symbols, like making the connection between '7' and the } \\
\text { word 'seven'; } \\
\text { - Graphic: Transcript mathematical signs; } \\
\text { - Practical: Solve mathematical Problems. }\end{array}$ \\
\hline $\begin{array}{l}\text { Mathematical } \\
\text { anxiety }\end{array}$ & $\begin{array}{l}\text { Do your pupils get easily frustrated, or unnaturally upset while completing a maths problem? } \\
\text { Do your pupils present nervousness or agitation before facing an assessable test or task? } \\
\text { Are your pupils determined and persistent while completing their Maths tasks? }\end{array}$ \\
\hline $\begin{array}{l}\text { Ways of } \\
\text { overcoming }\end{array}$ & $\begin{array}{l}\text { Please describe how you use inclusive, cooperative, agile or motivational methodologies during your } \\
\text { lessons (open question) }\end{array}$ \\
\hline $\begin{array}{l}\text { Support } \\
\text { needed }\end{array}$ & $\begin{array}{l}\text { Do you consider that you have the right tools to help a student who shows learning disabilities or } \\
\text { difficulties with Maths? } \\
\text { Do you need specific training in emotional skills to help students with Maths anxiety? } \\
\text { What are the main resources you need to help this kind of students: } \\
\text { - Human resources (guidance department, support staff...), } \\
\text { - Specific training, } \\
\text { - Methodological materials, } \\
\text { - Experience exchange, } \\
\text { - Other. }\end{array}$ \\
\hline
\end{tabular}


Mathematical learning disorders from the parents' point of view, answers in $\%(n=33)$

\begin{tabular}{|l|c|c|c|c|}
\hline \multicolumn{1}{|c|}{ Statements } & $\begin{array}{c}\text { Very } \\
\text { often }\end{array}$ & Often & $\begin{array}{c}\text { Some- } \\
\text { times }\end{array}$ & Never \\
\hline Your child is able to understand a mathematical problem, according to his age & 35 & 39 & 26 & 0 \\
\hline Your child counts on his fingers & 0 & 4 & 39 & 57 \\
\hline Your child shows some difficulties to understand mathematical terms or items & 0 & 17 & 57 & 26 \\
\hline $\begin{array}{l}\text { Your child makes mistakes in basic calculations (Adding, subtracting, } \\
\text { multiplying and dividing) }\end{array}$ & 4 & 17 & 74 & 4 \\
\hline $\begin{array}{l}\text { Your child can handle everyday situations that involve mathematical reasoning } \\
\text { (Money, time, comparing...) }\end{array}$ & 35 & 48 & 9 & 9 \\
\hline If your child makes it wrong at a mathematical task, does he keep trying? & 39 & 35 & 22 & 4 \\
\hline Your child asks you for more help than usual when doing mathematics tasks & 17 & 4 & 52 & 26 \\
\hline $\begin{array}{l}\text { Your child struggles to understand spatial concepts (Graphics, charts, up, down, } \\
\text { right or left) }\end{array}$ & 0 & 4 & 52 & 43 \\
\hline $\begin{array}{l}\text { Your child enjoys playing games such as puzzles, chess, checkers, memory } \\
\text { games... }\end{array}$ & 17 & 3 & 39 & 13 \\
\hline
\end{tabular}

\section{Results and Discussion}

The results of the parent survey are summarized in Table 2. They show that, in general, parents are very optimistic about their children's mathematics learning difficulties.

If the answers to the questions are judged by how often they are answered 'very often' or 'often' (in some statements - 'sometimes' or 'never'), then it must be concluded that about one-fifth still have difficulty learning mathematics, which is higher than in the whole world. Educational research shows that learning disabilities affect $10-15 \%$ of the population and about $6 \%$ of students suffer from dyscalculia. The most problematic area is basic calculations $-21 \%$ of respondents indicated a problem of this type. $25 \%$ of the respondents show that their children still have mathematical anxiety.

The results of the study also show that learning difficulties often occur between the ages of 9 and 11 . Seventy five percent of parents of children in this age group say that their children sometimes count on their fingers. All parents of children aged 6-8 years answered that their children ask for more help than usual when doing mathematics tasks. Results also show that $44 \%$ of children aged $12-16$ only sometimes can handle everyday situations that involve mathematical reasoning such as money, time, comparing, etc

When analysing the answers to the statements about mathematical anxiety, it is most often observed in the age group $12-16$ years (26\% of cases). But half of the parents of children aged 6-8 answer in the affirmative that their children speak positively about mathematics at home.

The parents' questionnaire also included the question of whether the parents themselves use a calculator for small calculations at home. Parents' responses to learning difficulties in mathematics were also analysed after answering this question. The results show that the less often parents use the calculator themselves, the less math learning disabilities their children have. In addition, families where parents do not use a calculator for daily calculations, as children more often play games such as puzzles, chess, checkers, memory games, etc. It shows, that parents' level of math skills (for example, they do not use a calculator in their daily calculations) affects their children's attitudes towards mathematics and their interest in various so-called brain games.

The parents' questionnaire also included a question about the difficulties their child faces in learning mathematics and how they are solved. Most common answers:

1) At school, it sometimes needs to be learned by heart to have a pace, but children learn better by understanding the connections;

2) Math concepts: nothing is explained individually in the classroom, but a more complex topic should be explained individually;

3) There is a lack of time on the part of the teacher to explain the topic more slowly;

4) The child often does not understand what the teacher wants from him;

5) To achieve good results in mathematics, most often parents attract a private tutor.

The results of the teacher survey show that the main mathematics learning difficulties among their student body are:

1) Solve mathematical problems $-68 \%$;

2) Understand mathematical concepts - 53\%;

3) Solve arithmetical calculations $-42 \%$; 
Teachers' answers $(\%)$ to questions about types of dyscalculia $(n=67)$

Table 3

\begin{tabular}{|l|c|c|c|c|}
\hline \multicolumn{1}{|c|}{ Statements } & $\begin{array}{c}\text { Very } \\
\text { often }\end{array}$ & Often & $\begin{array}{c}\text { Some- } \\
\text { times }\end{array}$ & Never \\
\hline $\begin{array}{l}\text { Do your pupils know how to articulate their doubts using mathematical } \\
\text { language according to their age? }\end{array}$ & 14 & 51 & 33 & 2 \\
\hline $\begin{array}{l}\text { Do your pupils understand the problems statements (spoken or written) and } \\
\text { the way to solve them? }\end{array}$ & 16 & 58 & 26 & 0 \\
\hline $\begin{array}{l}\text { Do your pupils have difficulty writing numbers clearly or keeping his work } \\
\text { neat when solving math problems? }\end{array}$ & 2 & 25 & 72 & 2 \\
\hline $\begin{array}{l}\text { Do your pupils struggle (make mistakes) while solving basic mental } \\
\text { arithmetic? }\end{array}$ & 5 & 25 & 63 & 7 \\
\hline
\end{tabular}

4) Transcript mathematical signs $-39 \%$;

5) Struggle to identify math signs like + and and to use them the right way or has trouble understanding number symbols, like making the connection between ' 7 ' and the word 'seven' - 19\%;

6) Struggle when comparing sizes or quantities $7 \%$.

Seven percent of teachers answered that their students do not have mathematics learning difficulties.

Table 3 provides summarised mathematics teachers answers to statements on types of dyscalculia.

Analysing these results in accordance with the methodology described above, the most problematic type of dyscalculia in Latvia is inability to perform mathematical operations and make calculations (operational and practical). Verbal and dyslexic disorders are less important, but so-called graphic disorders (transcription of mathematical signs) are the least important. According to teachers, mathematics learning difficulties are most common for basic school students. Teachers' responses suggest that mathematical anxiety is equally prevalent at all stages of education.

Summarizing the survey results in line with the conclusions about dyscalculia and mathematical anxiety in the scientific literature, students with dyscalculia often make errors in calculations and perform mathematical activities with difficulty; they do not choose age-appropriate calculation methods and use other problem-solving strategies (such as using fingers). They also have a hard time remembering arithmetic basic facts in long-term memory. Computational difficulties pose significant problems for their academic performance and practical application. Mathematical anxiety affects students' behaviour, for example, some students may be afraid of math lessons or avoid doing homework in math because they are afraid of negative emotions, and so on. Educational research shows that students with high levels of mathematical anxiety can develop negative attitudes towards mathematics and avoid any math-related activities. Dyscalculia and mathematical anxiety are different, but the signs and struggles can overlap. Some students may have both math anxiety and dyscalculia.

Teachers were asked if they could identify a case of dyscalculia among their students. Only $24.6 \%$ of respondents answered in the affirmative, $36.8 \%$ answered no, but $38.6 \%$ - that they do not know.

Children with dyscalculia need help in organizing and processing information and in everything related to numbers and mathematical concepts and activities. Appropriate teaching methods, appropriate visual and teaching materials, practical and active participation, use of information communication technologies, etc., can greatly facilitate the learning of mathematics (Tübele at al., 2013). Therefore, in the author's opinion, it is important to identify math learning difficulties and opportunities to overcome them, as well as teachers' readiness to do so and the necessary support to activate, motivate, inspire and engage students, to help overcome math learning difficulties and develop math skills. Thus, respondents were also asked to describe how they work with students with dyscalculia, what methods/ methodologies they use. Most common answers are:

1) Differentiated / individual approach;

2) Additional lessons / summer school;

3) Use of reminders (summaries);

4) Involving students in games where both numbers and arithmetic operations are written as elements in different form the result of which is that the student remembers these associations when he sees the specific symbol;

5) Reformulating the task in simpler words, explaining the rules, allowing the use of a calculator, etc.

More than half of the mathematics teachers surveyed (51\%) said that they do not have the right tools (skills, know-how and training) to help a student who experiences (shows) learning disabilities and 
difficulties with mathematics. Therefore, the main resources which teachers need to help this kind of students are:

1) Methodological materials $-84 \%$;

2) Experience exchange - $60 \%$;

3) Human resources (guidance department, support staff ...) $-50 \%$;

4) Specific training $-37 \%$.

\section{Conclusions}

1. The results of the research conducted within the framework of the research show that the difficulties of learning mathematics are assessed similarly by both parents and mathematics teachers, namely, about one-fifth of students have signs of dyscalculia, but $25 \%$ - mathematical anxiety.

2. The most pronounced type of dyscalculia in Latvia is an inability to perform mathematical operations and perform calculations (operational and practical). Verbal and dyslexic disorders are less important, but so-called graphic disorders (transcription of mathematical signs) are the least important. Mathematical anxiety is equally prevalent at all stages of education.

3. Most of the teachers surveyed are unable or unaware of how to determine whether a student has dyscalculia or mathematical anxiety and do not have appropriate tools to help a student with a learning disability / difficulty. Teachers think that methodological materials and exchanges of experience would raise qualifications to help these types of students.

4. Although the self-assessment method was used in the empirical study and the results cannot be generalized, as they are based only on the opinion of the respondents, this study is important because such studies have not been performed in Latvia before.

\section{Acknowledgements}

The study uses the results of parents' and teachers' surveys conducted within the framework of the Erasmus+ Strategic Partnership project No. 2020-1-LV01-KA201-077574 "Teaching Mathematics to Students with Dyscalculia and Mathematical Anxiety".

\section{References}

Ashcraft, M.H., \& Ridley, K.S. (2005). Math anxiety and its cognitive consequences: A tutorial review. J.I.D. Campbell (Ed.), Handbook of Mathematical Cognition (pp. 315-327). New York: Psychology Press.

Ashcraft, M.H., \& Krause, J.A. (2007). Working memory, math performance and math anxiety. Psychonomic Bulletin \& Review, 14(2), 243-248.

Büttner, G., \& Hasselhorn, M. (2011). Learning disabilities: Debates on definitions, causes, subtypes, and responses. International Journal of Disability, Development and Education, 58(1), 75-87.

Carey, E., Hill, F., Devine, A., \& Szücs, D. (2017). The Modified Abbreviated Math Anxiety Scale: A Valid and Reliable Instrument for Use with Children, 8(January), 1-13.

Devine, A., Hill, F., Carey, E., \& Szucs, D. (2017). Cognitive and Emotional Math Problems Largely Dissociate: Prevalence of Developmental Dyscalculia and Mathematics Anxiety. Journal of Educational Psychology. DOI: $10.1037 /$ edu0000222.

Dowker, A., Sarkar, A., \& Looi, C.Y. (2016). Mathematics anxiety: What have we learned in 60 years? Frontiers in psychology, 7, 1-16. DOI: 10.3389/fpsyg.2016.00508.

EC (2006). Recommendation of the European Parliament and of the Council of 18 December 2006 on key competences for lifelong learning (2006/962/EC). Official Journal of the European Union, L394, 10-18.

EC (2018). Annex to Proposal for a Council Recommendations on Key Competences for Life-long Learning. $A$ European Reference Framework, Brussels, 17.1.2018, COM(2018) 24 final. Retrieved March 5, 2021, from https://eur-lex.europa.eu/resource.html?uri=cellar:395443f6-fb6d-11e7-b8f5-01aa75ed71a1.0001.02/ DOC_1\&format=PDF.

Finlayson, M. (2014). Addressing math anxiety in the classroom. Improving Schools, 17(1), 99-115.

Hoffman, B. (2010). "I Think I Can, but I'm Afraid to Try": The role of self-efficacy beliefs and mathematics anxiety in mathematics problem-solving efficiency. Learning and Individual Differences, 20(3), $276-283$.

Kamann, M.P., \& Wong, B.Y. (1993). Inducing adaptive coping self-statements in children with learning disabilities through self-instruction training. Journal of Learning Disabilities, 26(9), 630-638. DOI: $10.1177 / 002221949302600913$.

Kosc, L. (1974). Development of dyscalculia. Journal of learning disabilities, 7 (3), 164-177.

Maloney, E.A., \& Beilock, S.L. (2012). Math anxiety. Who has it, why it develops, and how to guard against it. Trends in Cognitive Sciences, 16(8), 404-406. DOI: 10.1016/j.tics.2012.06.008.

Richardson, F.C., \& Suinn, R.M. (1972). The Mathematics Anxiety Rating Scale: Psychometric data. Journal of Counseling Psychology, 19(6), 551-554. DOI: 10.1037/h0033456. 
Rotzer, S., Loenneker, T., Kucian, K., Martin, E., Klaver, P., \& von Aster, M. (2009). Dysfunctional neural network of spatial working memory contributes to developmental dyscalculia. Neuropsychologia, 47, 2859-2865.

Tūbele, S., Landra, T., Šūmane, I., Burčaka, M., Laganovska, E., Kušnere, S., \& Vīgante, R. (2013). Metodiskais materiāls pedagogiem darbam ar izglītojamiem, kuriem ir mācīšanās traucējumi un redzes traucējumi (Methodological material for teachers to work with learners with learning disabilities and visual impairments). Retrieved February 15, 2021, from www.visc.gov.lv. (in Latvian).

Turkington, C., \& Harris, J.R. (2006). The Encyclopedia of Learning Disabilities: Second Edition. United States of America: American Bookworks. 